\title{
Beyond-brand effect of television food advertisements on food choice in children: the effects of weight status
}

\author{
Jason CG Halford ${ }^{1, *}$, Emma J Boyland ${ }^{1}$, Georgina M Hughes ${ }^{1}$, Leanne Stacey ${ }^{1}$, \\ Sarah McKean ${ }^{1}$ and Terence M Dovey ${ }^{1,2}$ \\ ${ }^{1}$ Kissileff Laboratory for the Study of Human Ingestive Behaviour, School of Psychology, Eleanor Rathbone \\ Building, Bedford Street South, University of Liverpool, Liverpool L69 7ZA, UK: ${ }^{2}$ Department of Psychology, \\ Staffordshire University, College Road, Stoke-on-Trent ST4 2DE, UK
}

Submitted 15 January 2007: Accepted 9 September 2007: First published online 16 November 2007

\begin{abstract}
Objective: To investigate the effect of television food advertising on children's food intake, specifically whether childhood obesity is related to a greater susceptibility to food promotion.

Design: The study was a within-subject, counterbalanced design. The children were tested on two occasions separated by two weeks. One condition involved the children viewing food advertisements followed by a cartoon, in the other condition the children viewed non-food adverts followed by the same cartoon. Following the cartoon, their food intake and choice was assessed in a standard paradigm.

Setting: The study was conducted in Liverpool, UK.

Subjects: Fifty-nine children (32 male, 27 female) aged 9-11 years were recruited from a UK school to participate in the study. Thirty-three children were normalweight (NW), 15 overweight (OW) and 11 obese (OB).

Results: Exposure to food adverts produced substantial and significant increases in energy intake in all children $(P<0 \cdot 001)$. The increase in intake was largest in the obese children $(P=0 \cdot 04)$. All children increased their consumption of high-fat and/ or sweet energy-dense snacks in response to the adverts $(P<0 \cdot 001)$. In the food advert condition, total intake and the intake of these specific snack items correlated with the children's modified age- and gender-specific body mass index score. Conclusions: These data suggest that obese and overweight children are indeed more responsive to food promotion, which specifically stimulates the intake of energy-dense snacks.
\end{abstract}

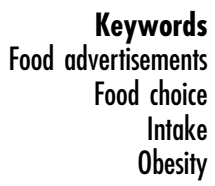

The worldwide trend in childhood overweight and obesity is now a well-characterised phenomenon ${ }^{(1)}$. Where national data are available, adiposity has increased in both pre-school and school-aged children in nearly every country studied. However, large variations in secular trends do appear across countries, and these relate to the degree of economic development and urbanisation ${ }^{(1)}$. Increased availability of highly palatable, energy-dense convenience foods and increasing levels of sedentary activity may specifically contribute to rising rates of childhood obesity. Certainly, consumption of fast foods and soft drinks has risen markedly during the same period of time $^{(2)}$. Given the link between childhood obesity and adult ill-health, how to mitigate these effects has now become an international health imperative ${ }^{(3)}$.

Strong associations between the duration of daily television (TV) viewing and children's adiposity have been reported in numerous studies ${ }^{(4-10)}$. Moreover, TV viewing behaviour predicts later adiposity, suggesting a causative role ${ }^{(9,11,12)}$. While this relationship is in part mediated by exercise ${ }^{(11)}$, much research has also demonstrated that TV viewing is also associated with specific differences in food intake and diet. Increased TV viewing in children and/or adolescents is associated with reduced fruit and vegetable consumption ${ }^{(13-16)}$, more snacking $^{(17,18)}$, and increased intake of unhealthy and decreased intake of healthy foods ${ }^{(19)}$. Van den Bulck and Van Meirlo found that every additional hour of TV viewed per day equated to an additional $653 \mathrm{~kJ}$ consumed ${ }^{(20)}$. TV viewing is thus related both to the type and the amount of food consumed.

A link between TV viewing and obesity is clearly a concern, as TV viewing is a popular leisure-time pursuit for children across the globe. In the UK, each week children watch an average of $17 \mathrm{~h}$ of programming (both children's and family), a majority of which is commercial, 
i.e. broadcasting adverts ${ }^{(21)}$. It has been shown that around half of the advertisements shown during children's programming in the UK are for food products, of which most are high in fat, sugar and/or salt ${ }^{(22-25)}$, although new regulations regarding such advertising have recently been introduced in the $\mathrm{UK}^{(26)}$. A recent US-based study estimated that between $27.2 \%$ and $36.4 \%$ of children's exposure to non-programme content was for foodrelated adverts ${ }^{(27)}$. These were for cereals $(27.6 \%)$, sweets (17.7\%), snacks (12.2\%), fast-food restaurants (12.0\%) and beverages $(8.8 \%)$. Numerous studies have shown that food adverts can alter children's preference for specific brands as the advertisers would intend ${ }^{(28-30)}$. However, more recent data suggest they can also, under certain circumstances, increase energy intake ${ }^{(31,32)}$.

A systematic review of the literature on the effects of advertising on consumption in children by Hastings et al. ${ }^{\text {(33) }}$ concluded that food promotion is having an effect, particularly on children's preferences, purchase behaviour and consumption'. The findings of the Hastings review would suggest that this form of brand promotion has clear effect beyond brand swapping, promoting a diet of energy-dense obesity-promoting foods. Certainly, it seems that children who watch more TV consume more of the most frequently advertised items, as well as less fruit, water and milk ${ }^{(34)}$. Generally it is TV viewing and not advert exposure that has been linked to childhood obesity. However, in a recent cross-cultural study which included data from the USA, Australia and eight European countries, a significant association between advert exposure and childhood obesity has been demonstrated ${ }^{(35)}$. Specifically, a clear association between the prevalence of childhood obesity and the number of adverts for sweet and/or fatty foods advertised per $20 \mathrm{~h}$ period of childspecific programming was found. It would seem logical then to infer that increased occurrence of obesity is caused by increased exposure to adverts promoting foods high in sugar and/or fat during viewing. However, if this is the case, are obese children more responsive to exposure to food adverts?

Our previous research has shown that recognition of food advertisements correlates with body mass index $(\mathrm{BMI})^{(31)}$. However, food advert exposure did not produce any clear weight-status-specific effects on children's intake or food choice. If food adverts have the same effect on the intake and food choice of all children, irrespective of weight status, can they really be contributing specifically to childhood obesity? In our previous research the sample size was small, and consequently the number of obese and overweight children included in the study was limited. Moreover, in the protocol, an advert recognition task preceded the food intake measurement and therefore this task may have interfered with the effects of our experimental manipulation on food cues. So what is still not certain is whether or not the effects of TV food advertising are more pronounced in obese and overweight children. Consequently, we decided to reexamine the effects of food adverts in a sample of children including a far greater number of obese and overweight individuals in order to determine the effects of weight status on the response.

In our previous study, the ability to correctly recognise food adverts was significantly associated with higher food intake following food advert exposure ${ }^{(31)}$. It was also found that obese children recognised a greater number, and a greater proportion, of TV food adverts compared with non-food TV adverts. They also recognised more TV food adverts than the normal-weight children. In our previous study we tested advert recognition prior to food intake $^{(31)}$. However, this cognitive task may have affected children's food intake, either by distracting them from the effects of the food adverts or by acting as food stimuli themselves. Therefore, in the present study, food intake measurements were not preceded by the recognition task.

It was hypothesised that: (1) food advert exposure would increase food intake and alter food preferences in children; (2) these effects would be more pronounced in the overweight and obese children; and (3) food advert recognition would be related to children's weight status.

\section{Methods}

\section{Participants}

Fifty-nine children (32 male, 27 female) aged between 9 years 6 months and 11 years 2 months (mean 10 years 2 months) were recruited from two classes of a UK school to participate in the study. This was an opportunity sample, no child or parent refused to participate; therefore the children were entirely representative of the two classes. In this study no children dropped out due to illness or for any other reason.

BMI was converted to a standard deviation (SD) score using the revised 1990 reference standards ${ }^{(36)}$. BMI was calculated using the standard formula of weight $(\mathrm{kg}) /$ [height $(\mathrm{m})]^{2}$, and these values were categorised as obese, overweight or normal weight based on published UK age- and gender-related norms ${ }^{(10,11)}$. Standard deviation from these norms ${ }^{(36,37)}$ for the whole sample was used in analyses to standardise for age- and gender-related differences. This method was used previously in Halford et $a l .{ }^{(32)}$. Using these established criteria, 33 (56\%) children were normal-weight (NW), 15 (25\%) were overweight (OW) and 11 (19\%) were obese (OB). This was a higher number and proportion of overweight and obese children than in our previous studies ${ }^{(31,32)}$

\section{Materials}

\section{Television advertisements}

Three videos were used, containing a collection of 10 non-food related adverts, a collection of 10 food-related 
adverts, and a cartoon. Advertisements were recorded from children's and family programming. The products featured in the adverts used in each condition are described in Table 1. Each advert was approximately $30 \mathrm{~s}$ in length, for a total advert exposure time in both conditions of $5 \mathrm{~min}$. These adverts were immediately followed by a 10 min cartoon; the same cartoon was used in both conditions.

\section{Foods and food intake measurement}

The children were given the opportunity to select and eat from an assortment of foods. The foods offered were: Quaker Snack-a-Jacks (cheese flavour); Haribo jelly sweets; Cadbury's chocolate buttons; Walker's potato crisps (ready salted flavour); and fruit (green seedless grapes). Each food item was chosen to represent a specific food category: low-fat savoury, low-fat sweet, highfat sweet, high-fat savoury and low energy density. The first four food categories were used previously in Halford et $a l^{(31)}$ and all five were used in Halford et $a l^{(32)}$. The number of foods offered to each child was limited to five choices due to constraints of space. The nutritional values of the foods used in the study are shown in Table 2.

\section{Study design}

This study utilised a within-subject, counterbalanced design with control (toy advert) and experimental (food advert) conditions. Each child underwent both conditions. For counterbalancing, the order of presentation varied within the sample, so that approximately half of the sample (one school class) took part in the control (toy advert) condition first, the other half of the sample took part in the food advert condition first to minimise order effects. The two sessions were held at the same time on each test day but two weeks apart.

\section{Procedure}

Two weeks prior to the study, the children were asked if they wished to take part and consent forms were given to their parents.

On each occasion, the children were told that they would be viewing adverts followed by a cartoon. After viewing, the children were divided into groups of four or five. Each child was then presented with five plates, containing one of each of the five foods in either a standard portion size or $50 \mathrm{~g}$ weight, whichever was the greater. The children were instructed that they could eat as little or as much food as they liked, and were asked not to eat from one another's plates. The children were also told that if they finished the portion of a particular food, more of that food would be provided if they wished. A number of children did request extra food. There was no time constraint; however, neither session lasted beyond $20 \mathrm{~min}$. Once the children had finished eating, the remaining uneaten food was re-weighed. After the second session, weight and height measurements were taken individually, in private, with a member of school staff present at all times.

\begin{tabular}{|c|c|c|}
\hline Order & Toy adverts & Food adverts \\
\hline 1 & Twister board game & Fish fingers (fish sticks) \\
\hline 2 & Scooby Doo Talking Dog & Fast-food burger chain (1) \\
\hline 3 & Transformer Robots & Baked beans \\
\hline 4 & Rocket Rollercoaster & Chocolate-flavoured rice breakfast cereal \\
\hline 5 & Spin the Bottle board game & Cheese and biscuit snack \\
\hline 6 & Guess Who? & Fast-food burger chain (2) \\
\hline 7 & Styling Head and Make Up & Oat-based breakfast cereal \\
\hline 8 & Mouse Trap board game & White chocolate bar \\
\hline 9 & Hungry Huey game & Fruit-flavoured sweets \\
\hline 10 & Walking Pup & High-fat savoury potato snack \\
\hline
\end{tabular}

Table 2 Nutritional values of food items used in this study (per $100 \mathrm{~g}$ )

\begin{tabular}{|c|c|c|c|c|c|}
\hline Nutritional information & $\begin{array}{l}\text { Walker's Ready } \\
\text { Salted Crisps }\end{array}$ & $\begin{array}{l}\text { Quaker's Snack-a-Jacks, } \\
\text { cheese flavour }\end{array}$ & $\begin{array}{c}\text { Cadbury's Chocolate } \\
\text { Buttons }\end{array}$ & $\begin{array}{l}\text { Haribo Starmix jelly } \\
\text { sweets }\end{array}$ & $\begin{array}{c}\text { Green seedless } \\
\text { grapes }\end{array}$ \\
\hline Energy value (kcal) & $530 \cdot 0$ & $409 \cdot 0$ & 493.0 & $344 \cdot 0$ & $68 \cdot 8$ \\
\hline$(\mathrm{MJ})$ & $2 \cdot 20$ & 1.71 & 2.06 & 1.44 & 0.29 \\
\hline Fat $(\mathrm{g})$ & 34.0 & 8.5 & $28 \cdot 1$ & 0.2 & 0.2 \\
\hline of which saturates $(\mathrm{g})$ & 2.6 & 1.5 & $17 \cdot 4$ & 0.1 & 0.1 \\
\hline Carbohydrate (g) & 49.0 & $75 \cdot 0$ & 53.4 & 79.0 & $18 \cdot 1$ \\
\hline of which sugars $(\mathrm{g})$ & 0.5 & 6.0 & $52 \cdot 8$ & 63.4 & 15.5 \\
\hline Protein $(\mathrm{g})$ & 6.5 & 8.0 & 7.3 & 6.6 & 0.8 \\
\hline Fibre $(\mathrm{g})$ & 4.0 & 1.0 & 0.6 & 0.3 & 0.9 \\
\hline Sodium (q) & 0.6 & 1.1 & 0.1 & 0.0 & 0.0 \\
\hline
\end{tabular}




\section{Analysis}

All intake data collected adhered to the assumptions for parametric data, therefore analysis took the form of analysis of variance (ANOVA and MANOVA where appropriate) and $t$ tests. Post hoc comparisons used appropriate repeated-measures or independent-sample $t$ tests. All analyses were completed using the Statistical Package for the Social Sciences statistical software package, version 14 for personal computer (SPSS Inc., Chicago, IL, USA).

\section{Results}

\section{Total food intake}

A mixed ANOVA was performed on the total energy consumed by the children between the three weight status categories. Across the group as a whole, total energy intake was significantly higher after exposure to food adverts than after the control (toy) adverts $(F(1,56)=210 \cdot 751$; $P<0 \cdot 001)$. There was also a between-participant effect of BMI on total energy intake between the two advert conditions $(F(2,56)=3 \cdot 398 ; P=0 \cdot 04)$, with food advert exposure increasing total food intake in the NW $(t(36)=10 \cdot 454$; $P<0.001)$, OW $(t(14)=11.285 ; \quad P<0.001)$ and $\mathrm{OB}$ $(t(10)=5.815 ; \quad P<0.001)$ children by $89 \%, 100 \%$ and $155 \%$, respectively (see Fig. 1).

A significant interaction with BMI status and advert type was also observed $(F(2,56)=7 \cdot 076 ; P=0 \cdot 002)$. The significant difference in intake between the three weight status groups was in the food advert condition only $(F(2,58)=6.259 ; P=0.004)$, as all participants consumed a similar amount of food following the control (toy) adverts $(F(2,58)=0.112 ; P=0.894)$. Specifically, following exposure to food adverts, $\mathrm{OB}$ children consumed more food than the NW $(t(42)=3.674 ; P=0.001)$ and OW $(t(24)=1.798 ; P=0 \cdot 043)$ children.

In addition, there was a significant positive correlation between BMI SD score and energy intake after exposure to the food adverts $(r(59)=0.465 ; P<0.001)$ (see Fig. 2 ).

\section{Intake of individual foods}

A MANOVA (violation of sphericity) examining the effects of adverts and weight status on food choice was performed. This produced a significant interaction between food choice and advert condition $(F(4,53)=76 \cdot 140$; $P<0.001)$, whereby food advert exposure increased the intake of all food items (except Snack-a-Jacks) in the group as a whole (see Table 3). With regard to energy intake, in the control (toy advert) condition, children consumed significantly more energy from jelly sweets and chocolate than from crisps, significantly more energy from crisps than from grapes, and significantly more energy from grapes than from Snack-a-Jacks (all tests $P<0 \cdot 001$ ). While this ranking did not change per se after exposure to the food adverts, the greatest increase in

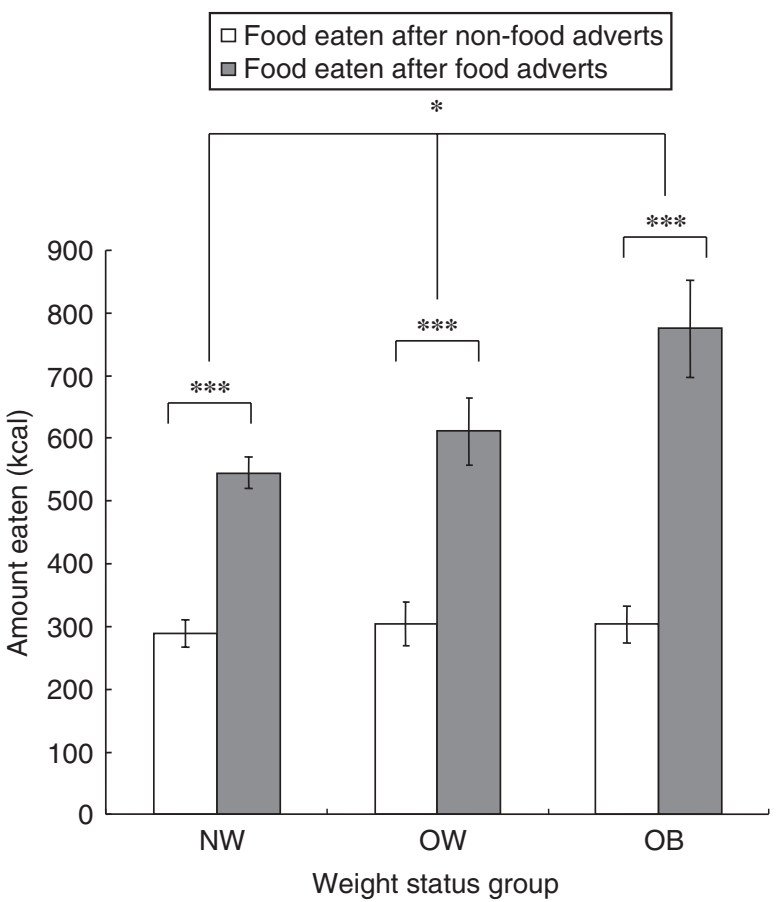

Fig. 1 Amounts of food eaten by the normal-weight (NW), overweight $(\mathrm{OW})$ and obese $(\mathrm{OB})$ children in the two advertisement conditions. Values are means, with standard error of the mean shown by vertical bars. Mean values were significantly different: ${ }^{\star} P<0.05,{ }^{\star \star \star} P<0.001$. For conversion of energy values to MJ, multiply kcal by 4.184 and divide by 1000

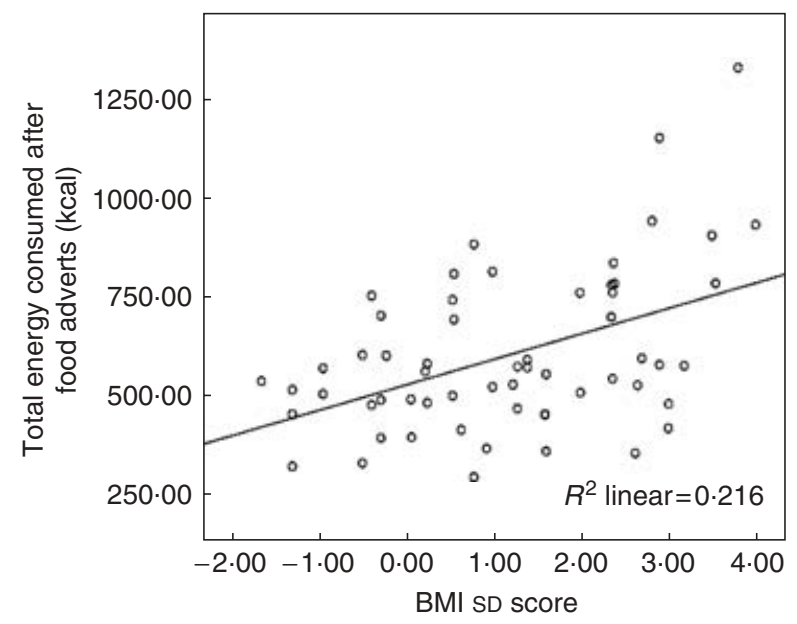

Fig. 2 Correlation between body mass index (BMI) standard deviation (SD) score and food intake after exposure to the food adverts. BMI converted to SD for age and gender based on published norms. For conversion of energy values to $\mathrm{MJ}$, multiply kcal by 4.184 and divide by 1000

intake was seen in chocolate (152\%), crisps (92\%) and jelly sweets (90\%), and then in grapes (46\%).

There was also a significant three-way interaction of food consumption between food type, advert condition 
Table 3 Mean intake $(\mathrm{g})$ of each food item in both conditions

\begin{tabular}{|c|c|c|c|c|c|c|c|c|c|c|c|c|c|c|c|c|c|}
\hline \multirow[b]{3}{*}{ Food item } & \multicolumn{8}{|c|}{ After toy adverts } & \multicolumn{8}{|c|}{ After food adverts } & \multirow{3}{*}{$\begin{array}{l}\text { Significance } \\
\text { (whole group) }\end{array}$} \\
\hline & \multicolumn{2}{|c|}{ NW } & \multicolumn{2}{|c|}{ OW } & \multicolumn{2}{|c|}{$\mathrm{OB}$} & \multicolumn{2}{|c|}{ Whole group } & \multicolumn{2}{|c|}{ NW } & \multicolumn{2}{|c|}{ OW } & \multicolumn{2}{|c|}{ OB } & \multicolumn{2}{|c|}{ Whole group } & \\
\hline & Mean & SEM & Mean & SEM & Mean & SEM & Mean & SEM & Mean & SEM & Mean & SEM & Mean & SEM & Mean & SEM & \\
\hline Crisps & $6 \cdot 4$ & $1 \cdot 1$ & 8.8 & 2.0 & $10 \cdot 2$ & $2 \cdot 7$ & $7 \cdot 7$ & 1.0 & $12 \cdot 4$ & 1.5 & $15 \cdot 2$ & 2.8 & $22 \cdot 3$ & 3.0 & 14.9 & 1.3 & $P<0.001$ \\
\hline Snack-a-Jacks & $3 \cdot 3$ & 0.6 & 1.7 & 0.4 & 7.5 & 1.9 & 3.7 & 0.5 & 4.0 & 0.7 & 2.9 & 0.8 & $9 \cdot 3$ & 3.0 & 4.7 & 0.7 & NS, $P=0.052$ \\
\hline Chocolate buttons & $18 \cdot 7$ & $2 \cdot 7$ & 20.9 & 4.5 & $17 \cdot 7$ & 3.3 & $19 \cdot 1$ & $2 \cdot 0$ & 42.9 & 3.7 & 42.5 & 7.6 & 71.9 & 9.8 & 48.2 & 3.6 & $P<0.001$ \\
\hline Jelly sweets & 33.3 & 3.4 & 30.4 & 5.9 & 28.7 & 7.5 & 31.7 & $2 \cdot 8$ & 55.7 & 4.9 & $72 \cdot 2$ & $8 \cdot 2$ & $58 \cdot 8$ & 8.7 & 60.5 & 3.8 & $P<0.001$ \\
\hline Grapes & 48.1 & 6.5 & 61.7 & 9.8 & 45.5 & $13 \cdot 1$ & 51.0 & $5 \cdot 0$ & $76 \cdot 7$ & $10 \cdot 8$ & $77 \cdot 7$ & 2.4 & 64.4 & $17 \cdot 2$ & 74.7 & 7.5 & $P=0.001$ \\
\hline
\end{tabular}

NW, normal weight; OW, overweight; OB, obese; SEM, standard error of the mean.

and weight status $(F(8,108)=3 \cdot 429 ; P=0 \cdot 001)$. Using planned post hoc one-way ANOVAs, it was shown that this significant interaction was due to differences in food intake between the weight status groups. The OB group ate significantly more chocolate buttons and Snack-aJacks following the food adverts than both the OW and NW children, and more crisps than the NW children (all tests $P<0.05)$. The $\mathrm{OB}$ group also ate significantly more Snack-a-Jacks in the control (toy advert) condition than both the OW $(t(24)=3.438 ; P=0.002)$ and the NW children $(t(42)=2 \cdot 867 ; P=0 \cdot 006)$. There was no statistical difference in the intake of jelly sweets or grapes between weight status groups in either the food advert or control (toy advert) condition.

There were significant positive correlations between BMI SD score and energy intake from chocolate buttons $(r(59)=0.322 ; P=0.013)$, crisps $(r(59)=0.329 ; P=0 \cdot 011)$ and jelly sweets $(r(59)=0 \cdot 273, P=0 \cdot 037)$ after exposure to the food adverts. In the control (toy advert) condition, a weak correlation between BMI SD score and crisp intake was observed $(r(59)=0 \cdot 268 ; P=0 \cdot 04)$.

\section{Discussion}

As predicted, the effect of food advert exposure produced the greatest response in the obese children. The intake response in overweight children was also significantly greater than in the normal-weight children. This is the first clear between-weight-status effect on intake in response to food advert exposure to be demonstrated in our studies. This may have been in part because of the greater proportion and total number of overweight and obese children we were able recruit to this study. Despite a smaller sample and lower proportional obesity, our previous research had found that BMI correlates with food advert recognition ${ }^{(31)}$ suggesting that there was an underlying difference in the impact food adverts had on children of differing weight-status, hence the rationale for this study. However, in the previous study, food advert exposure produced equivalent increases in food intake in all children irrespective of their weight status. In fact, in the previous study, trends for weight status differences in overall food intake were apparent in both control (toy advert) and food advert conditions. In contrast, in the present study no weight status differences in total food intake in the control (toy advert) condition were apparent.

Critically, these data provide the first clear definitive picture of an exaggerated intake response to food advert exposure based on weight status. In response to the food adverts, the obese children increased their intake by $1.97 \mathrm{MJ}$ ( $471 \mathrm{kcal})$ from the control (toy advert) condition, compared with $1.28 \mathrm{MJ}(306 \mathrm{kcal})$ in the overweight and $1.05 \mathrm{MJ}(250 \mathrm{kcal})$ in the normal-weight children. The increase in intake in the overweight group was primarily driven by an increase in the intake of jelly sweets (0.60 MJ, $143 \mathrm{kcal})$ and chocolate $(0.48 \mathrm{MJ}, 114 \mathrm{kcal})$. Similarly, the increase in intake in the obese children was primarily driven by an increase in chocolate consumption $(1.03 \mathrm{MJ}, 245 \mathrm{kcal})$. This suggests that it is the effect of food advert exposure on the intake of sweet, energydense foods which differentiates the weight status groups. Moreover, in the food advert condition, total energy intake and intake of all the high-energy-density foods (jelly sweets, chocolate and crisps) were significantly and positively correlated with the children's standardised BMI scores.

Given that TV viewing is associated with current $\operatorname{adiposity}^{(4-10)}$ and predicts future weight gain ${ }^{(9,11,12)}$, we believe that obese and overweight children may request more foods merely because of increased advert exposure. Certainly a direct association between TV advertisement exposure and obesity has recently been demonstrated ${ }^{(35)}$. Advert exposure in general has been clearly linked to increased requests for specific items ${ }^{(38,39)}$ and this seems to be equally true for food adverts as for toy adverts. Chamberlain et al. ${ }^{(40)}$ demonstrated that total TV viewing and total media exposure are associated with subsequent food and drink requests. Brody et al. ${ }^{(28)}$ showed that advert exposure increased demands for specific advertised food items in subsequent shopping trips. Similarly, Marquies et $a l .{ }^{(41)}$ also found that time in front of the TV increased requests to parents for advertised foods. In addition, Arnos ${ }^{(42)}$ noted that during TV viewing, over $40 \%$ of children asked their parents to purchase food items they had seen advertised. 
Given the nature of the foods promoted on TV, if these requests translated into purchases and consumption this could only have a negative impact on $\operatorname{diet}^{(22-25,27,28)}$. However, research is needed to determine if the mere degree of exposure and not individual differences in responsiveness predict these weight status differences. The notion that the obese may be more responsive to external food cues is also well established in the literature $^{(43)}$. Perhaps the relationship between food promotion and obesity is in part independent of total TV viewing time or total advert exposure?

With regard to the experimental manipulation, these results clearly replicate our previous findings that exposure to food advertisements increases food intake in children $^{(31)}$. Advert exposure produced varying changes in intake of all of the differing food items offered to the children. The effect was greatest for the three most energy-dense foods (high in fat and/or sugar). The intake of the low-fat savoury food item was very low. Halford et $a l^{(31)}$ also showed that in both the control (toy advert) condition and the food advert condition, the least consumed snack was the low-fat savoury option. There are probably two interrelated factors mediating the effects of TV viewing on energy intake: first, the type of foods that are easiest to consume while viewing; and second, the type of foods most promoted during viewing (both during family programming and in many countries still promoted during children's programming also $)^{(22-25,27,28)}$. These items are often snack foods high in fat and sugar, and are likely to promote positive energy balance.

In this study, the low-fat savoury item was again the least preferred, as commented on before ${ }^{(32)}$. Low-fat savoury snack items probably do not feature significantly in children's habitual diets and consequently it is hard to find one that children will consume a substantial amount of when presented alongside more familiar and favoured items $^{(31,32)}$. There are obvious limitations to the use of only four or five food items to assess children's habitual taste preferences and the effect of advert exposure on them. However, the number of food items which realistically can be offered to each child is limited. Questionnaire-based tools are more appropriate if a more comprehensive assessment of the effect of food advert exposure on food preference and food choice is required.

What is particularly distinct in these data is that the total increase in energy intake and the increases in the intake of each of the foods were far greater in magnitude than previously reported, with the total energy intake doubling after exposure to food adverts. In this respect, the results contrast markedly with our previous findings. In the present study, the stimuli and the foods offered were very similar to those offered before ${ }^{(31)}$; therefore it is most likely that the change in procedure altered the response. The removal of the advert recognition test reduced the time from advert exposure to the experimental eating opportunity from over $15 \mathrm{~min}$ (cartoon viewing and $5 \mathrm{~min}$ to complete the recognition task) to just $10 \mathrm{~min}$ (cartoon viewing only), strengthening the salience of the cue. However, this change in magnitude of the effect was probably also due to the fact that only one rather than two events occurred between the stimuli exposure and the food eating opportunity. While the effect of a specific exposure can initially be quite dramatic, the effects dissipate fairly quickly especially if attention is diverted to a cognitive task such as recognition. Whether increased duration between adverts and eating opportunity, or distraction is the more potent effect at dissipating the effects of food adverts on subsequent intake remains to be tested.

This was an experimental study in a relatively small but (in terms of distribution of body weight) a fairly representative sample of UK children in this age group. Rather than using an opportunity sample, another approach would have been to recruit children in each of the three weight status categories to produce three weight status groups with equal numbers; however, matching these groups for age, gender and socio-economic background may be difficult. Caution must be taken when generalising the results of small-scale experimental studies to real-world behaviour. However, these data provide clear evidence of weight status differences, both in terms of total energy intake and in food choice, in response to food advert exposure, differences that were not apparent from our previous work. Moreover, they again demonstrate the statistically significant effect of advert exposure on children's food choice and total energy intake. These factors may well be critical in explaining the link between TV viewing, advert exposure and childhood obesity.

\section{Acknowledgements}

This study was funded wholly by the University of Liverpool. The original study was designed by J.C.G.H. and T.M.D.; the experimental procedures were piloted, the data were collected and a preliminary analysis was performed by S.M. and L.S.; G.M.H. and E.J.B. also helped in the development of the study protocol, the preparation of study materials and purchasing of study foods, generated additional data and analysed the full data set. All six authors contributed to the first draft of the manuscript. J.C.G.H. and E.J.B. handled submission and revision. J.C.G.H. has recently received research support from Lipid Nutrition and has also recently worked with Danone UK and GlaxoSmithKline, all on unrelated projects. E.J.B.'s postgraduate study is supported by the School of Psychology, University of Liverpool. The authors wish to acknowledge our colleagues in the Human Ingestive Behaviour Laboratory, in particular Dr Joanne Harrold and Professor Tim Kirkham, for their time and support. 


\section{References}

1. Wang $\mathrm{Y}$ \& Lobstein $\mathrm{T}$ (2006) Worldwide trends in childhood overweight and obesity. Int J Pediatr Obes $\mathbf{1}$, $11-25$.

2. St-Onge MP, Keller KL \& Heymsfield SB (2003) Changes in childhood food consumption patterns: a cause for concern in light of increasing body weights. Am J Clin Nutr 78, 1068-1073.

3. Lobstein T \& Baur LA (2005) Policies to prevent childhood obesity in the European Union. Eur J Public Health 15, 576-579.

4. Bernard L, Lavallee MA, Gray-Donald K \& Delisle H (1995) Overweight in Cree schoolchildren and adolescents associated with diet, low physical activity, and high television viewing. J Am Diet Assoc 95, 800-802.

5. Anderson RE, Crespo CJ, Bartlett SJ, Cheskin LJ \& Pratt M (1998) Relationship of physical activity and television watching with body weight and level of fatness among children. JAMA 179, 938-942.

6. Crespo CJ, Smit E, Troiano RP, Bartlett SJ, Macera CA \& Andersen RE (2001) Television watching, energy intake and obesity in US children. Arch Pediatr Adolesc Med $\mathbf{1 5 5}$, 360-365.

7. Dennison BA, Erb TA \& Jenkins PL (2002) Television viewing and television in bedroom associated with overweight risk among low-income preschool children. Pediatrics 109, 1028-1035.

8. Kaur H, Choi WS, Mayo MS \& Harris KJ (2003) Duration of television watching is associated with increased body mass index. J Pediatr 143, 506-511.

9. Proctor MH, Moore LL, Gao D, Cupples LA, Bradlee ML, Hood MY \& Ellison RC (2003) Television viewing and change in body fat from preschool to early adolescence: The Framingham Children's Study. Int J Obes Relat Metab Disord 27, 827-833.

10. Reilly JJ, Armstrong A, Dorosty AR, Emmett PM, Ness A, Rogers I, Steer C \& Sherriff A (2005) Early life risk factors for obesity in childhood: cohort study. BMJ 330, $1357-1359$.

11. Jago R, Baranowski T, Baranowski JC, Thompson D \& Greaves KA (2005) BMI from 3-6 y of age predicted by TV viewing and physical activity, not diet. Int J Obes (Lond) 29, 557-564.

12. Viner RM \& Cole TJ (2005) Television viewing in early childhood predicts adult body mass index. J Pediatr 147, 429-435.

13. Ortega RM, Andrés P, Requejo AM, López-Sobaler AM, Redondo MR \& González-Fernández M (1996) Influence of the time spent watching television on the dietary habits, energy intake and nutrient intake of a group of Spanish adolescents. Nutr Res 16, 1467-1470.

14. Lowry R, Wechsler H, Galuska DA, Fulton JE \& Kann K (2002) Television viewing and its associations with overweight, sedentary lifestyle, and insufficient consumption of fruits and vegetables among US high school students: differences by race, ethnicity, and gender. J Sch Health $\mathbf{7 2}$, 413-421.

15. Boynton-Jarrett R, Thomas TN, Peterson KE, Wiecha J, Sobol AM \& Gortmarker SL (2003) Impact of television viewing on fruit and vegetable consumption among adolescents. Pediatrics 112, 1321-1326.

16. Matheson DM, Killen JD, Wany Y, Varadt A \& Robinson T (2004) Children's food consumption and television viewing. Am J Clin Nutr 79, 1088-1094.

17. Francis LA, Lee Y \& Birch LL (2003) Parental weight status and girls' television viewing, snacking, and body mass indexes. Obes Res 11, 143-151.

18. Snoek HM, Van Strien T, Janssens JMAM \& Engels RCME (2006) The effect of television viewing on adolescents' snacking: individual difference explained by external, restrained and emotional eating. J Adolesc Health 39, 448-451.

19. Woodward DR, Cummings FJ, Ball PJ, Williams HM, Hornsby H \& Boon JA (1997) Does television affect teenagers' food choices? J Hum Nutr Diet 10, 229-235.

20. Van der Bulck J \& Van Mierlo J (2004) Energy intake associated with television viewing in adolescents, a cross sectional study. Appetite 43, 181-184.

21. Office of Communications (2004) Childhood obesity: food advertising in context. http://www.ofcom.org.uk/research/ tv/reports/food_ads/ (accessed June 2006).

22. Furnham A, Abramsky S \& Gunter B (1997) A cross-cultural content analysis of children's television advertisements. Sex Roles 37, 91-99.

23. Lewis MK \& Hill AJ (1998) Food advertising on British children's television: a content analysis and experimental study with nine-year olds. Int J Obes Relat Metab Disord 22, 206-214.

24. Harrison K \& Marske AL (2005) Nutritional content of foods advertised during the television programs children watch most. Am J Public Health 95, 1568-1574.

25. Neville L, Thomas M \& Bauman A (2005) Food advertising on Australian television: the extent of children's exposure. Health Promot Int 20, 105-112.

26. Office of Communications (2007) Television advertising of food and drink products to children: Final statement. http://www.ofcom.org.uk/consult/condocs/foodads_new/ statement// (accessed June 2006).

27. Powell LM, Szczypka G \& Chaloupka FJ (2007) Exposure to food adverting on television among US children. Arch Pediatr Adolesc Med 161, 553-560.

28. Brody GH, Stoneman Z, Lane TS \& Sanders AK (1981) Television food commercials aimed at children, family grocery shopping, and mother-child interactions. Fam Relat 30, 435-439.

29. Borzekowski DLG \& Robinson TN (2001) Effect of commercials on preschoolers. Nutr Res Newslett 20, 1-2.

30. Gunter B, Oates C \& Blades M (2005) Advertising to Children on TV. Content, Impact and Regulation. Mahwah, NJ: Lawrence Erlbaum Associates.

31. Halford JCG, Gillespie J, Brown V, Pontin EE \& Dovey TM (2004) The effect of television (TV) food advertisements/ commercials on food consumption in children. Appetite $\mathbf{4 2}$, 221-225.

32. Halford JCG, Boyland E, Hughes G, Oliveira L \& Dovey TM (2007) Beyond-brand effect of television (TV) food advertisements/commercials on caloric intake and food choice of 5 to 7 year old children. Appetite 49, 263-267.

33. Hastings G, Stead M, McDermott L, Forsyth A, MacKintosh AM \& Rayner M (2004) Review of Research on the Effects of Food Promotion to Children. Report prepared for the Food Standards Agency. Glasgow: Centre for Social Marketing, The University of Strathclyde.

34. Vereecken CA \& Maes L (2006) Television viewing and food consumption in Flemish adolescents in Belgium. Soz Praventivmed 51, 311-317.

35. Lobstein T \& Dibb S (2005) Evidence of a possible link between obesogenic food advertising and child overweight. Obes Rev 6, 203-208.

36. Cole TJ, Freeman JV \& Preece MA (1995) Body-mass index reference curves for the UK, 1990. Arch Dis Child 73, 25-29.

37. Cole TJ, Bellizi MC, Flegal KM \& Dietz WH (2000) Establishing a standard definition for child overweight and obesity worldwide: international survey. BMJ 320, $1240-1243$.

38. Buijzen M \& Valkenburg PM (2000) The impact of television advertising on children's Christmas wishes. J Broadcast Electron Media 44, 456-470. 
39. Pine KJ \& Nash A (2002) Dear Santa: the effects of television advertising on young children. Int J Behav Dev 26, 529-539.

40. Chamberlain LJ, Wang Y \& Robinson TN (2006) Does children's screen time predict requests for advertised products? Cross sectional and prospective analysis. Arch Pediatr Adolesc Med 160, 363-368.
41. Marquies M, Filion Y \& Dafenais F (2005) Does eating while watching television influence children's food-related behaviours? Can J Diet Pract Res 66, 12-18.

42. Arnos YA (2006) The effects of television advertisements on children's food purchasing requests. Pediatr Int 48, 138-145.

43. Schacter S (1971) Emotions, Obesity and Crime. New York: Academic Press. 